\title{
ACTUALIZACIÓN ACADÉMICA PARA ADMINISTRADORES EDUCATIVOS EN ZONAS DE ATENCIÓN PRIORITARIA, ANÁLISIS DE UNA EXPERIENCIA
}

Ileana Vargas Jiménez ${ }^{l}$

\section{Resumen}

El siguiente artículo refiere al proyecto de extensión que nació como una necesidad de actualizar los conocimientos de los y las profesionales en administración educativa en ejercicio de sus funciones, ubicados en zonas de atención prioritaria de San José y Heredia y se coordina con el Programa PROMECUM, del Ministerio de Educación Pública.

Palabras claves: administración educativa, zona urbana, calidad.
Abstract

The author comments about a project that starts as a response for the updating requirement of administrative educational professionals who works in educational institutions located in poor communities. The project was developed in the provinces of San Jose and Heredia, through the PROMECUM program, working in coordination with the Public Department of Education.

Keywords: education, administrative management.

\section{Antecedentes del proyecto de extensión}

$\mathrm{L}$ a administración educativa es vista como una disciplina que garantiza la eficiencia y es clave en la organización del sistema escolar. En esta función, se deben promover cambios para mejorar la calidad de los procesos

1 Licenciada en Educación Preescolar, con una Maestria en Administración Educativa de la Universidad de Nuevo México, Estados Unidos, Directora de la División de Educación para el Trabajo. Esta investigación contó con la colaboración de los académicos: Adolfo Aguilar Herrera, Virginia Cerdas Montano, Adyeri Marin Calderón.

Recibido: 3 de noviembre-2006 - Aprobado: 30 de noviembre-2006 
educativos, respondiendo para ello a las necesidades educativas de los contextos en donde se desarrolla el proyecto.

Como principal característica, destaca que es un proceso dinámico, innovador, renovador y participativo. Para que estas características se concreticen en los centros educativos, necesariamente, se requieren directoras y directores con un perfil basado en competencias, además de actitudes personales que les permitan desarrollar sus talentos y ejercer un liderazgo pedagógico para crear el sentido de sus instituciones.

Se pretende con este proyecto contribuir a que los funcionarios en administración educativa, logren procesos de diagnósticos colectivos y establezcan mecanismos de automejoramiento en sus centros educativos.

En estos contextos tradicionalmente excluidos, hay problemas de deserción, de agresión familiar, violencia doméstica, entre otros. Los y las docentes que laboran en esos centros, por lo general, no viven en esas comunidades, lo que hace que las situaciones escolares sean más difíciles de manejar para las directoras y los directores.

El fin es favorecer a los y las estudiantes, padres y madres de familia, docentes, comunidad y la formación de futuros ciudadanos, quienes se integrarán, de forma activa, a la sociedad.

\section{Se señalan los objetivos del proyecto}

1. Identificar las necesidades de actualización que requieren los directores y las directoras de la región educativa de San José y Heredia en zonas de atención prioritaria.

2. Proponer estrategias de intervención que permiten el abordaje de diversos temas que soliciten los y las participantes.

3. Propiciar espacios de reflexión que llevan al mejoramiento continuo en la ejecución de la administración educativa.

4. Desarrollar un plan de trabajo que contribuya al mejoramiento de la gestión administrativa, curricular y humana en la zona de San José, en escuelas y colegios de atención prioritaria.

5. Establecer mecanismos de evaluación y seguimiento necesarios para el óptimo funcionamiento del proyecto de capacitación. 


\section{¿Cuáles productos se esperan obtener durante la ejecución del proyecto de extensión?}

- Un diagnóstico de participación de los involucrados.

- Una matriz de planificación, donde se establezcan las estrategias por seguir para el cumplimiento de lo planteado.

- Memorias de los talleres, foros, así como charlas realizadas.

- Una memoria de los aspectos tratados en el proceso de inducción.

- La elaboración de los Modelos de Gestión Pedagógica para cada centro educativo participante.

Para la ejecución de lo planteado anteriormente se diseña un Plan Estratégico:

Proceso de inducción: Se les brinda a las directoras y los directores de los centros educativos participantes un proceso de inducción, que les permite visualizar el proceso y las metas esperadas que se pretenden alcanzar conjuntamente.

Diagnóstico participativo: Se aplican instrumentos diagnósticos que permitan hacer una lectura de la realidad; este proceso es particularmente importante, ya que de aquí se parte para responder a las necesidades sentidas por los participantes: la planificación de estrategias, los temas de capacitación que se abordan en las diferentes sesiones, el lugar más accesible para todos y la metodología que se empleará.

Planificación curricular estratégica: La oferta del diseño curricular es una construcción social en este proceso, pues los participantes develan sus múltiples necesidades, para responder, de manera efectiva y eficiente, ante las demandas del contexto en donde están inmersos sus centros educativos.

Capacitación: Esta etapa consiste en el desarrollo de sesiones sistemáticamente planificadas, que abordan temas con especialistas, invitados especiales o los mismos miembros del equipo de investigadores.

Aplicación de gestión: Es en esta etapa cuando las directoras y los directores de los centros educativos, ponen en práctica sus saberes conceptuales y los convierten en saberes operativos, transfiriendo conocimientos de la teoría a la acción. Se conforman equipos de apoyo para cada centro educativo, liderados por el director o la directora. Estos equipos realizan con los otros actores sociales de cada comunidad educativa, un diagnóstico y a su vez sus propias alternativas de solución para los problemas o situaciones detectadas. 
Finalmente, cada centro educativo concluye esta etapa con un producto único y pertinente a su contexto: Un Modelo de Gestión Pedagógica. Dicho modelo se socializa con las autoridades competentes para obtener los avales e implementarlo en cada centro educativo.

Informe final: Como parte del proceso, el equipo de investigadores elabora un informe final, con la sistematización de los hallazgos, conclusiones y recomendaciones que puedan ser utilizadas en procesos de mejoras para otros centros educativos o experiencias similares.

Compartir la investigación: En esta etapa, tanto el equipo de investigadores, como las directoras y los directores de los centros educativos socializan la experiencia, con las autoridades de la Universidad Nacional, Ministerio de Educación Pública, otros colegas y grupos interdisciplinarios interesados en procesos de mejora proactivos.

\section{¿Qué se ha realizado?}

- Contacto con diferentes entidades del gobiemo anterior para obtener los avales y el apoyo al proyecto.

- Diagnóstico de necesidades de actualización y de la disposición al cambio de las y los administradores educativos.

- Desarrollo de sesiones de actualización con las directoras y los directores.

- Conformación de equipos de apoyo en cada centro educativo participante.

- Visita a los centros educativos y presentación del proyecto a los equipos de apoyo.

- $\quad$ Elaboración de un autodiagnóstico de cada centro educativo.

- Reuniones de retroalimentación con cada equipo de apoyo.

- Contacto con diferentes entidades del nuevo gobierno para mantener el aval y el apoyo al proyecto.

- Reuniones periódicas de seguimiento con los equipos de apoyo para la revisión y detalles finales de los Modelos de Gestión Pedagógica.

\section{¿Qué está por realizarse?}

- $\quad$ Entrega definitiva de los Modelos de Gestión Pedagógica.

- Avales del grupo de investigadores a los modelos propuestos por los diferentes centros educativos. 
- $\quad$ Presentación ante las autoridades de la Universidad Nacional.

- Retroalimentación de las autoridades de la Universidad Nacional.

- Presentación ante las autoridades del Ministerio de Educación Pública y otras entidades afines.

- Obtener avales para realizar los cambios requeridos para la implementación de los modelos.

- Implementación, verificación y ajuste de los modelos en cada centro educativo.

- Compartir la experiencia hacia otros centros educativos.

- Definir procesos necesarios en cuanto a: procesos de los centros educativos, perfil del administrador educativo, perfiles de docentes y administrativos, perfiles de estudiantes y necesidades de apoyo inter e intrainstitucional.

\section{Proyecto de actualización para administradores educativos Problemas en la Administración Educativa Resumen}

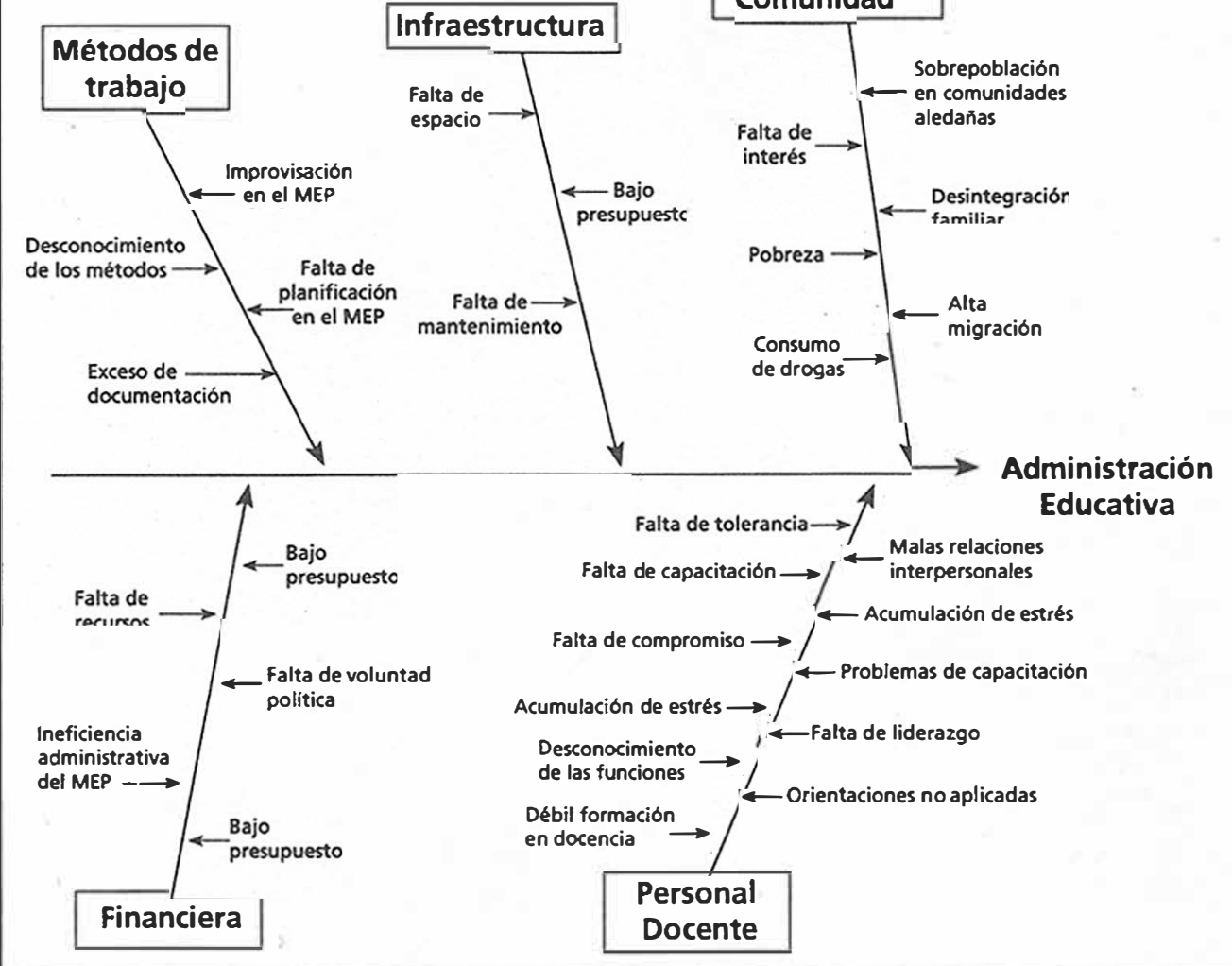


En este diagrama de Ishikaua, se puede visualizar cómo perciben las directoras y los directores su labor en sus centros educativos y cuáles son los mayores obstáculos que se les presentan para ejercer una gestión eficiente y eficaz. Entre los aspectos que se develan en este estudio, se pueden citar: los métodos de trabajo, la infraestructura, la comunidad, el área financiera y el personal docente.

Finalmente, el proyecto pretende que los involucrados logren cambios sustanciales desde las escuelas y, de esta manera, el director y la directora puedan lograr los objetivos propuestos. 


\section{REFERENCIA}

División de Educación para el Trabajo. (2005). Proyecto actualización académica para Administradores Educativos en Zonas de Atención Prioritaria. Universidad Nacional. 